\title{
Telecardiographic measurements for device migration: A useful tool for follow-up
}

\author{
Datih Avni Bayraktar, ${ }^{1}$ (D) Muge Tasdemir Mete, ${ }^{2}$ (D) Murat Sargin, ${ }^{2}$ (D) Sevinc Bayer Erdogan, ${ }^{2}$ \\ (D) Murat Bastopcu, ${ }^{2}$ (D) Ozlem Yildirimturk, ${ }^{2}$ (D) Gokcen Orhan, ${ }^{2}$ (D) Serap Aykut Aka ${ }^{2}$ \\ ${ }^{1}$ Department of Cardiovascular Surgery, Mus State Hospital, Mus, Turkey \\ ${ }^{2}$ Department of Cardiovascular Surgery, Dr. Siyami Ersek Thoracic and Cardiovascular Surgery Training and Reserch Hospital, Istanbul, Turkey
}

\begin{abstract}
OBJECTIVE: Pump thrombosis in left ventricular assist device (LVAD) patients is an important cause of mortality and morbidity. Inflow cannula migration is a predisposing factor for pump thrombosis. Telecardiographic measurements can be used to follow up apical cannula deviation. In this study, we aimed to evaluate the migration of the inflow cannulas in patients with LVADs using angle measurements on telecardiograms

METHODS: Twenty-three patients who were implanted left ventricular assist devices in our clinic between February 2013 and April 2016 were included in our study. During the first year of follow-up, changes in angle measurements on postoperative $1^{\text {st }}, 3^{\text {rd }}, 6^{\text {th }}$, and $12^{\text {th }}$ month telecardiograms were compared against the incidence of device thrombus and serum Lactate Dehydrogenase (LDH) levels.

RESULTS: Patients who were diagnosed with device thrombosis had more change in inflow cannula angles than patients without device thrombus ( $\mathrm{p}<0.05$ at $6^{\text {th }}$ and $12^{\text {th }}$ months). Patients with higher LDH values had more parallel angular changes at all intervals, and the change in angle was statistically significant at $3^{\text {rd }}, 6^{\text {th }}$ and $12^{\text {th }}$ months $(p<0.05)$.

CONCLUSION: This study shows that it is possible to track the migration of inflow cannulas in patients with left ventricular heart failure using telecardiograms. The correlation between angle change and LDH levels and embolic events may suggest that telecardiographic follow up of angles may be a useful tool for ventricular assist devices teams for early detection of thrombus.

Keywords: Heart failure; thrombosis; ventricular assist device.

Cite this article as: Bayraktar FA, Tasdemir Mete M, Sargin M, Bayer Erdogan S, Bastopcu M, Yildirimturk O, et al. Telecardiographic measurements for device migration: A useful tool for follow-up. North Clin Istanb 2020;7(2):106-111.
\end{abstract}

T eft ventricular assist devices (LVAD) allow bridgLing of end-stage heart failure patients to definitive treatments or sustain survival as destination therapy $[1,2]$ Despite a reasonable period of survival with an increased quality of life, device-related complications are not rare. Pump thrombosis is among the most severe complications [3]. A combination of antiplatelet and anticoagulant treatments is advised against pump thrombosis [4, 5]. However, pump thrombosis may still occur under seemingly effective anticoagulation. The migration of the assist device within the mediastinum is shown to be a predisposing factor for pump thrombosis. It has been postulated that the change in the angle of inflow cannula as a result of device migration causes changes in flow metrics that lead to thrombus formation within the device [6-8].

In this study, we aimed to evaluate the ability of the telecardiogram in assessing device migration and its utility in aiding the detection of pump thrombosis. 


\section{MATERIALS AND METHODS}

\section{Patient Selection}

Heart failure patients who received an LVAD between February 2013 and April 2016 (38 months) were retrospectively analyzed in this study. Patients aged $>18$ years who were regularly followed up in our center for at least one year after device implantation, with telecardiographies at $1,3,6$, and 12 months and INR values consistently between $2.5-3.5$ were identified and included in this study.

\section{Data Collection}

Demographic variables, preoperative and postoperative echocardiographic data were retrospectively collected. Angle measurements were made on anteroposterior telecardiographic images on postoperative day 1 , and at 1 , 3, 6, 12 months. Serum Lactate Dehydrogenase (LDH) levels on the same dates as the teleradiography images were recorded. LDH levels 2.5 times above the upper normal limit were accepted as high. The Institutional Committee of Haydarpasa Numune Training and Research Hospital approved the study protocol. This study conformed with the principles of the Declaration of Helsinki.

\section{Technique for Angle Measurements}

Correct inflow cannula position during LVAD implantation is routinely confirmed with transesophageal echocardiography (TEE) to assure a cannula position parallel to the interventricular septum. During the follow up, transthoracic echocardiography (TTE) and, when needed, TEE are utilized to evaluate LVAD patients. Certain objective measurement criteria were defined to utilize telecardiogram in the evaluation of the inflow cannula positions. Therefore, to prevent mistaken measurements and to assure a standard in the evaluation, images in which sternal wires were in line with the vertebral borders were chosen for angle measurements. A line parallel to the sternal wires, and therefore the vertebral borders, was extended and a second line perpendicular to the first was drawn. This second transverse line and a line through the inflow cannula were connected to acquire the angle in between, termed the "parallel angle" (Fig. 1).

A second angle was measured for patients implanted with a HeartMate II device (Thoratec Corp., Pleasanton, CA, USA) between the inflow cannula and device body, termed the "device angle" (Fig. 2).

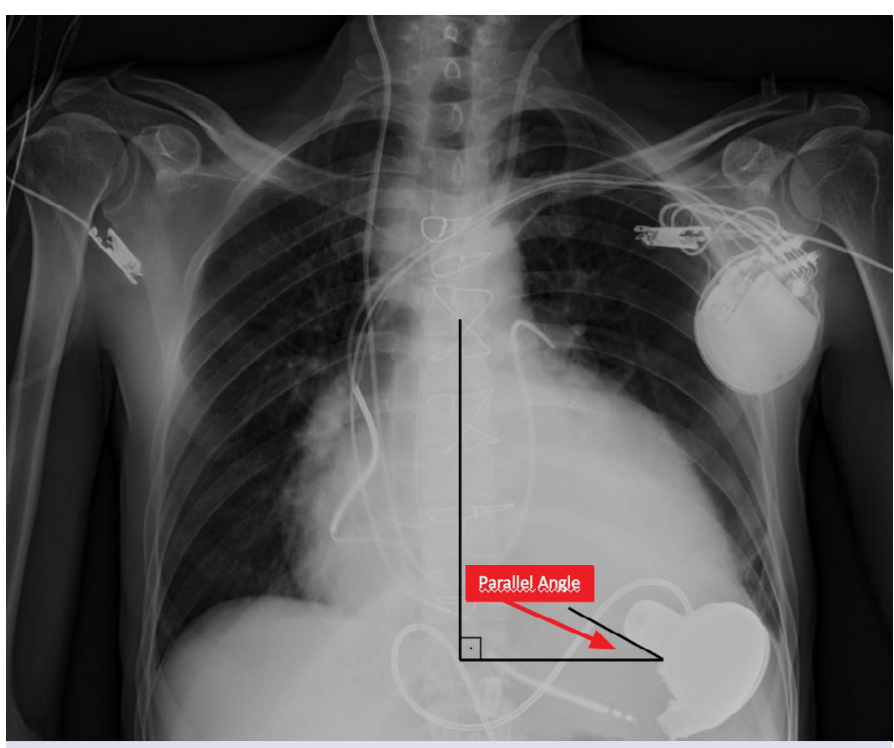

FIGURE 1. Parallel angle of the HearWare.

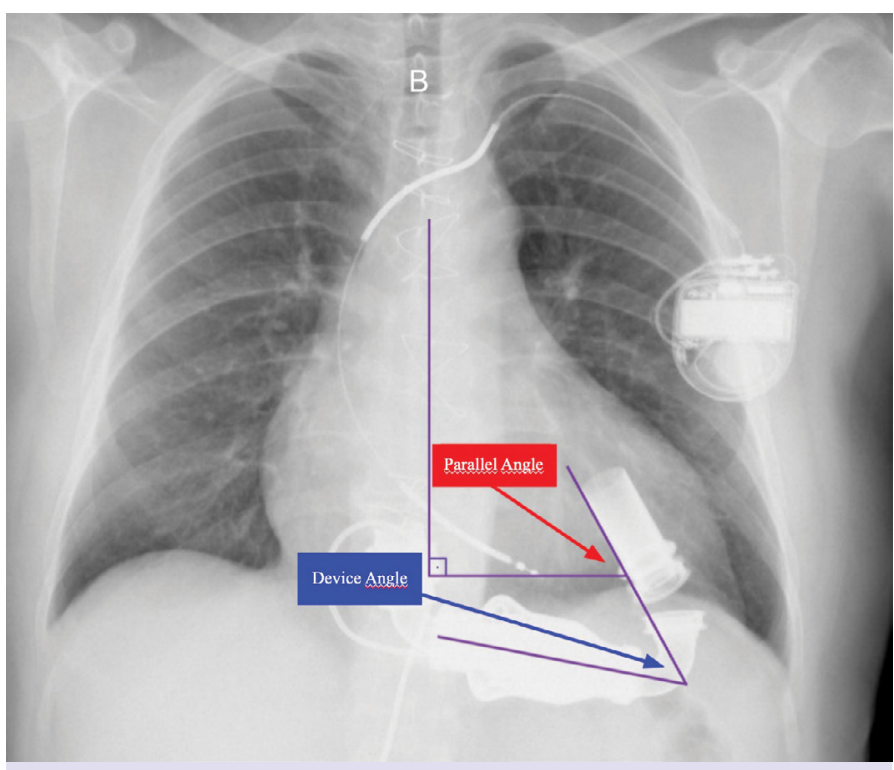

FIGURE2. Parallel angle and device angle of the HeartMate II.

\section{Device Thrombosis}

Patients with ischemic cerebrovascular events, LDH levels 2.5 times above the upper normal limit, high device power usage, and device thrombosis determined by echocardiography were included in the device thrombosis group.

\section{Statistical Analysis}

NCSS (Number Cruncher Statistical System) 2007 (Kaysville, Utah, USA) was used to perform statistical analysis. Besides descriptive statistics (mean, standard 
TABLE 1. Baseline characteristics

\section{Characteristics}

Age (year); Mean \pm SD

Gender; \%

Male

Female

BMI $\left(\mathrm{kg} / \mathrm{m}^{2}\right) ;$ Mean \pm SD

Etiology; \%

Dilated

Ischemic

Intermacs; \%

2

3

4

SD: Standard deviation; BMI: Body mass index.

deviation, median, frequency, minimum, maximum), the Mann-Whitney $U$ test was applied to compare quantitative data without normal distribution. Fisher's Exact test was applied to compare quantitative data. $P$ values $<0.05$ were accepted for significance.

\section{RESULTS}

Thirty-eight patients had received an LVAD between February 2013 and April 2016 in our institution. 23 patients met the inclusion criteria and were included in this study. 18 patients were implanted with HeartMate II and five patients with a HeartWare (Medtronic, Minneapolis, MN, USA) LVAD. The baseline characteristics of the patients are given in Table 1 .

Among all LVAD patients in our clinic, the rate of clinically evident thrombosis was $16 \%$, while among the 23 patients included in this study the rate was $26 \%$. Only one of these patients required device exchange. Of the six patients with pump thrombosis, the implanted device was HeartMate II. None of the five patients in the study with HeartWare developed pump thrombosis. No pump thrombosis was observed in any of the patients that could not be included in this study.

Change in the parallel angle for HeartWare inflow cannula was lower than HeartMate II in all measurements. A higher degree of migration was detected in patients with HeartMate II devices; however, this difference was not statistically significant $(\mathrm{p}>0.05)$ (Table 2 ).
TABLE 2. Comparison of parallel angle changes according to device

\begin{tabular}{lccc} 
& \multicolumn{3}{c}{ Device } \\
\cline { 2 - 3 } $\begin{array}{l}\text { Time } \\
\text { (month) }\end{array}$ & $\begin{array}{c}\text { HeartWare } \\
(n=5)\end{array}$ & $\begin{array}{c}\text { HeartMate II } \\
(n=18)\end{array}$ & $\mathrm{p}$ \\
& Mean \pm SD & Mean \pm SD & \\
\hline 1 & $4.00 \pm 2.55$ & $4.50 \pm 4.85$ & 0.735 \\
3 & $4.80 \pm 3.63$ & $6.22 \pm 5.45$ & 0.765 \\
6 & $6.20 \pm 5.67$ & $8.00 \pm 6.25$ & 0.575 \\
12 & $4.40 \pm 2.07$ & $8.22 \pm 5.62$ & 0.191 \\
\hline
\end{tabular}

SD: Standard deviation.

TABLE 3. Comparison of parallel angle changes and LDH level

\begin{tabular}{lccc} 
& \multicolumn{2}{c}{ LDH } & \\
\cline { 2 - 3 } $\begin{array}{l}\text { Time } \\
\text { (month) }\end{array}$ & $\begin{array}{c}\text { Normal } \\
(n=9) \\
\text { Mean } \pm \text { SD }\end{array}$ & $\begin{array}{c}\text { Elevated } \\
(n=14) \\
\text { Mean } \pm S D\end{array}$ & $p$ \\
\hline 1 & $3.0 \pm 2.35$ & $5.29 \pm 5.22$ & 0.374 \\
3 & $3.22 \pm 3.38$ & $7.64 \pm 5.31$ & 0.031 \\
6 & $4.11 \pm 4.65$ & $9.86 \pm 5.89$ & 0.005 \\
12 & $4.44 \pm 2.92$ & $9.29 \pm 5.65$ & 0.040 \\
\hline
\end{tabular}

*Elevated: Level above 2.5 times normal at least for once. SD: Standard deviation; LDH: Serum lactate dehydrogenase.

Levels of LDH values were compared against changes in the change parallel angle, as shown in Table 3. Patients with higher changes in the parallel angle of the inflow cannula had higher LDH values at all measurement points. This difference was significant in the $3^{\text {rd }}, 6^{\text {th }}$, and $12^{\text {th }}$ months $(p<0.05$ at three and 12 months, $\mathrm{p}<0.01$ at six months). The same significance $(p<0.05)$ was obtained at three and six months when only HeartMate II patients were analyzed at three and six months (Table 4). HeartWare patients were not analyzed due to the low number of patients with this device. However, the increase in $\mathrm{LDH}$ values with the changes in device angle for HeartMate II patients was not found to be significant (Table 5).

Comparison of patients with and without pump thrombosis for changes in the parallel angle is given in Table 6. Patients with device thrombosis had higher 
TABLE 4. Comparison of parallel angle changes and LDH level for HeartMate II

\begin{tabular}{lccc} 
Time & \multicolumn{2}{c}{ LDH level } & \\
\cline { 2 - 3 } (month) & $\begin{array}{c}\text { Normal } \\
(n=5) \\
\text { Mean } \pm S D\end{array}$ & $\begin{array}{c}\text { Elevated* } \\
(n=13) \\
\text { Mean } \pm \text { SD }\end{array}$ & $p$ \\
\hline 1 & $2.20 \pm 1.64$ & $5.38 \pm 5.42$ & 0.320 \\
3 & $1.60 \pm 1.82$ & $8.00 \pm 5.35$ & 0.010 \\
6 & $2.40 \pm 1.67$ & $10.15 \pm 6.03$ & 0.005 \\
12 & $4.60 \pm 3.58$ & $9.62 \pm 5.74$ & 0.067 \\
\hline
\end{tabular}

*Elevated: Level above 2.5 times normal at least for once. SD: Standard deviation; LDH: Serum lactate dehydrogenase.

TABLE 5. Comparison of HeartMate II device angle measurements and LDH level

\begin{tabular}{lccc}
\multicolumn{3}{c}{ LDH level } & \\
\cline { 2 - 3 } Time & $\begin{array}{c}\text { Normal } \\
(\mathrm{n}=5)\end{array}$ & $\begin{array}{c}\text { Elevated* } \\
(\mathrm{n}=13)\end{array}$ & $\mathrm{p}$ \\
& Mean \pm SD & Mean $\pm \mathrm{SD}$ & \\
\hline $1^{\text {st }}$ day & $35.20 \pm 4.71$ & $38.85 \pm 14.61$ & 0.921 \\
$1^{\text {st }}$ month & $37.40 \pm 6.80$ & $41.77 \pm 13.48$ & 0.693 \\
$3^{\text {rd }}$ month & $39.60 \pm 7.99$ & $39.62 \pm 1296$ & 0.621 \\
$6^{\text {tt }}$ month & $40.60 \pm 7.99$ & $41.31 \pm 15.11$ & 0.656 \\
$12^{\text {th }}$ month & $41.80 \pm 7.79$ & $41.08 \pm 14.37$ & 0.554 \\
\hline
\end{tabular}

*Elevated: Level above 2.5 times normal at least for once. SD: Standard deviation; LDH: Serum lactate dehydrogenase.

changes in parallel angle compared to patients without device thrombosis at all measurement times. This difference was significant at six and 12 months $(p<0.05)$. When the devices were compared for changes in the parallel angle, HeartWare patients had lower parallel angle measurements than HeartMate II patients. Changes in the parallel angle were higher at all times in HeartMate II patients at all measurement points, but this difference was not statistically significant $(\mathrm{p}>0.05)$.

\section{DISCUSSION}

LVADs are a feasible treatment option for improving the quality of life and survival in late-stage heart failure patients bridged to transplant or implanted as destination therapy
TABLE 6. Comparison of parallel angle change and thromboembolic events

\begin{tabular}{lccc} 
& \multicolumn{2}{c}{ Thrombus } & \\
\cline { 2 - 3 } Time & $\begin{array}{c}\text { (month) } \\
\text { Mean } \pm \text { SD }\end{array}$ & $\begin{array}{c}+(n=6) \\
\text { Mean } \pm S D\end{array}$ & $p$ \\
1 & $3.82 \pm 3.21$ & $6.00 \pm 6.96$ & 0.888 \\
3 & $5.18 \pm 5.34$ & $8.00 \pm 3.85$ & 0.106 \\
6 & $6.35 \pm 6.15$ & $11,17 \pm 4.40$ & 0.032 \\
12 & $6.12 \pm 4.73$ & $11.00 \pm 5.44$ & 0.049 \\
\hline
\end{tabular}

-: Thrombus not detected; +: Thrombus detected; SD: Standard deviation.

[9]. Device complications are an important cause of morbidity and mortality in LVAD patients. Pump thrombosis among the most significant complications [10]. Several factors play a role in pump thrombosis, and migration of device body and inflow cannula are considered to increase the risk for its occurrence $[6,8]$. In clinical practice, echocardiographic evaluation provides information on suspected device migration. We investigated whether a simpler imaging method, the telecardiogram, could be useful for the same purpose. Echocardiography for LVAD patients requires specific expertise and is optimally performed by the same clinician during follow up. These conditions may not be available at all times in centers that are not experienced in following up heart failure patients. We investigated whether under such conditions, a simpler and easily accessible telecardiogram could be utilized.

A limited number of studies exist on the detection of device migration using telecardiographic measurements. Taghavi et al. studied the angle between the inflow cannula and device body at the time of implantation and found an increased risk for pump thrombosis when the angle was smaller than 55 degrees [7]. They noted that device migration detected by the change in the angle of inflow cannula did not significantly correlate with pump thrombosis. They also reported that the depth of the device pocket where the LVAD body is placed decreased with time.

In a later study, Adamson et al. studied angles on telecardiographies of LVAD patients [6]. The amount of change in the angle of the device body was found to be greater in patients with device thrombosis. This study looked at the angle between the inflow cannula and a line vertical to the vertebra, somewhat different from the parallel angle we studied. The change in this angle over time after 
implantation in all their LVAD patients was also found to be significant, with a 1-degree change detected at the end of the 2-year follow up. Our study using the parallel angle detected a 2-degree change, which was not statistically significant. A different study by Han et al. used the same angle measurements as Taghavi et al. to arrive at different results [11]. Mean change in the angle of inflow cannula was not significantly correlated with device thrombosis.

Sorensen et al. used computer tomography measurements to analyze the relationship between change in inflow cannula angle and device thrombosis and they found a significant correlation [8]. This study was different from the other studies in that the absolute value of the angle change was used to compare patients with device thrombosis against those without. The degree of the inflow cannula may be increased or decreased, which may cancel each other during the calculation of mean change despite the existence of migration. Thus, different from most of the other studies, we used the absolute value of the changes in inflow angles to compare patients, similar to Sorensen et al.

HeartWare patients were found to have lower parallel angle measurements than HeartMate II patients. A possible explanation for this difference could be the low number of HeartMate II patients included in this study. Further studies with a considerable number of patients with different devices need to be designed to compare the devices for changes in angles.

LDH increase is evident in case of pump thrombosis $[12,13]$. Akin et al. have shown that a threefold increase in $\mathrm{LDH}$ has an $88 \%$ specificity and $97 \%$ sensitivity as a marker of hemolysis [13]. When LDH levels were compared with changes in parallel angle at the same time points, patients with a higher change in the angle also had higher LDH levels. This correlation supports our view that pump thrombosis and hemolysis are more frequent in patients with a considerable change in the telecardiographically measured angle.

The prevalence of pump thrombosis varies in studies $[14,15]$. Taghavi et al. found a $22.4 \%$ prevalence of pump thrombosis [7], while Simon Maltais et al. with their surgical precautions detected a $4.8 \%$ rate of pump thrombosis after the 6-month follow-up [16]. Device thrombosis was seen in $16 \%$ of the LVAD patients in our clinic, while the rate was $26 \%$ among patients that met the inclusion criteria with available telecardiogram and echocardiography data. Pump thrombosis remains a vital issue for LVAD patients, and the telecardiogram could prove useful in its detection when other imaging methods are not readily available.

\section{Conclusion}

Device migration is an important risk factor for pump thrombosis in LVAD patients. Our study showed that telecardiograms are a useful tool in detecting changes in cannula angles. The change in parallel angle, corresponding to the severity of device migration, is correlated with an elevation in serum LDH. The telecardiogram, as a simple and inexpensive method, can be used to assess LVAD migration.

Ethics Committee Approval: The Haydarpasa Numune Training and Research Hospital Clinical Research Ethics Committee granted approval for this study (date: 24.01.2017, number: 2017/44).

Conflict of Interest: No conflict of interest was declared by the authors.

Financial Disclosure: The authors declared that this study has received no financial support.

Authorship Contributions: Concept - FAB, MS; Design - FAB, MS, SAA; Supervision - SAA, GO; Materials - MB, MS, MTM; Data collection and/or processing - MB, OY, MTM; Analysis and/or interpretation - SAA, GO, OY; Writing - FAB, MTM, MB; Critical review - OY, MTM, SBE.

\section{REFERENCES}

1. Starling RC, Naka Y, Boyle AJ, Gonzalez-Stawinski G, John R, Jorde U, et al. Results of the post-U.S. Food and Drug Administration-approval study with a continuous flow left ventricular assist device as a bridge to heart transplantation: a prospective study using the INTERMACS (Interagency Registry for Mechanically Assisted Circulatory Support). J Am Coll Cardiol 2011;57:1890-8. [CrossRef]

2. Rose EA, Gelijns AC, Moskowitz AJ, Heitjan DF, Stevenson LW, Dembitsky W, et al; Randomized Evaluation of Mechanical Assistance for the Treatment of Congestive Heart Failure (REMATCH) Study Group. Long-term use of a left ventricular assist device for end-stage heart failure. N Engl J Med 2001;345:1435-43. [CrossRef]

3. Starling RC, Moazami N, Silvestry SC, Ewald G, Rogers JG, Milano $\mathrm{CA}$, et al. Unexpected abrupt increase in left ventricular assist device thrombosis. N Engl J Med 2014;370:33-40. [CrossRef]

4. Boyle AJ, Russell SD, Teuteberg JJ, Slaughter MS, Moazami N, Pagani FD, et al. Low thromboembolism and pump thrombosis with the HeartMate II left ventricular assist device: analysis of outpatient anticoagulation. J Heart Lung Transplant 2009;28:881-7. [CrossRef]

5. John R, Kamdar F, Liao K, Colvin-Adams M, Miller L, Joyce L, et al. Low thromboembolic risk for patients with the Heartmate II left ventricular assist device. J Thorac Cardiovasc Surg 2008;136:1318-23.

6. Adamson RM, Mangi AA, Kormos RL, Farrar DJ, Dembitsky WP. Principles of HeartMate II implantation to avoid pump malposition and migration. J Card Surg 2015;30:296-9. [CrossRef]

7. Taghavi S, Ward C, Jayarajan SN, Gaughan J, Wilson LM, Mangi AA. Surgical technique influences HeartMate II left ventricular assist device 
thrombosis. Ann Thorac Surg 2013;96:1259-65. [CrossRef]

8. Sorensen EN, Hiivala NJ, Jeudy J, Rajagopal K, Griffith BP. Computed tomography correlates of inflow cannula malposition in a continuousflow ventricular-assist device. J Heart Lung Transplant 2013;32:65457. [CrossRef]

9. Frazier OH, Rose EA, Oz MC, Dembitsky W, McCarthy P, Radovancevic B, et al; HeartMate LVAS Investigators. Left Ventricular Assist System. Multicenter clinical evaluation of the HeartMate vented electric left ventricular assist system in patients awaiting heart transplantation. J Thorac Cardiovasc Surg 2001;122:1186-95. [CrossRef]

10. Rose EA, Levin HR, Oz MC, Frazier OH, Macmanus Q, Burton NA, et al. Artificial circulatory support with textured interior surfaces. A counterintuitive approach to minimizing thromboembolism. Circulation 1994;90:II87-91.

11. Han JJ, Gaffey AC, Sooppan R, Hung G, Venkataraman C, Phillips E, et al. HeartMate II Left Ventricular Assist Device Geometry on Chest Radiograph Does Not Correlate with Risk of Pump Thrombosis. ASAIO J 2016;62:128-32. [CrossRef]

12. Feldman D, Pamboukian SV, Teuteberg JJ, Birks E, Lietz K, Moore SA, et al; International Society for Heart and Lung Transplantation. The 2013 International Society for Heart and Lung Transplantation Guidelines for mechanical circulatory support: executive summary. J Heart Lung Transplant 2013;32:157-87. [CrossRef]

13. Akin S, Soliman OI, Constantinescu AA, Akca F, Birim O, van Domburg RT, et al. Haemolysis as a first sign of thromboembolic event and acute pump thrombosis in patients with the continuous-flow left ventricular assist device HeartMate II. Neth Heart J 2016;24:134-42.

14. Goldstein DJ, John R, Salerno C, Silvestry S, Moazami N, Horstmanshof $\mathrm{D}$, et al. Algorithm for the diagnosis and management of suspected pump thrombus. J Heart Lung Transplant 2013;32:667-70. [CrossRef]

15. Whitson BA, Eckman P, Kamdar F, Lacey A, Shumway SJ, Liao KK, et al. Hemolysis, pump thrombus, and neurologic events in continuous-flow left ventricular assist device recipients. Ann Thorac Surg 2014;97:2097-103. [CrossRef]

16. Maltais S, Kilic A, Nathan S, Keebler M, Emani S, Ransom J, et al; PREVENT Study Investigators. PREVENtion of HeartMate II Pump Thrombosis Through Clinical Management: The PREVENT multi-center study. J Heart Lung Transplant 2017;36:1-12. [CrossRef] 